\title{
Correlation between anthropometric measurements and activity level on length and diameter of semitendinosus tendon autograft in knee ligament surgery: A prospective observational study
}

\author{
Tarun Goyal $^{1}$, Souvik Paul ${ }^{2, *}$, Lakshmana Das ${ }^{3}$, and Arghya Kundu Choudhury ${ }^{3}$ \\ 1 Additional Professor, Department of Orthopaedics, All India Institute of Medical Sciences, Rishikesh 248201, India \\ 2 MCh Fellow (Arthroplasty and Joint Reconstruction), Department of Orthopaedics, All India Institute of Medical Sciences, Rishikesh \\ 248201, India \\ 3 Junior Resident, Department of Orthopaedics, All India Institute of Medical Sciences, Rishikesh 248201, India
}

Received 22 September 2019, Accepted 31 March 2020, Published online 25 June 2020

\begin{abstract}
Introduction: Preoperative estimation of graft parameters can be useful while using hamstring grafts in knee ligament surgeries. Anthropometric parameters may be an easy way to predict the length and diameter of hamstring tendons. A prospective study was conducted to find the correlation between different anthropometric parameters and activity level of the patient on the length and diameter of the graft. Separate regression equations for males and females were also derived for easy prediction. Methods: Data were obtained from 95 patients who underwent arthroscopic anterior cruciate ligament reconstruction with autologous hamstring tendon graft. Variables studied were age, sex, height, weight, body mass index (BMI), thigh circumference, thigh length, Tegner activity level, diameter (double and quadruple) and length of semitendinosus tendon graft. Results: Height of the patient had strong correlation with graft length $(r=0.41, p<0.001)$, double diameter $(r=0.29, p=0.008)$ and quadruple diameter $(r=0.3$, $p=0.006)$. Weight of the patients had strong positive correlation with graft length $(r=0.34, p=0.002)$ and quadruple diameter $(r=0.34, p=0.002)$. Thigh length was found to be positively correlating with graft length $(r=0.43$, $p<0.001)$, double diameter $(r=0.29, p=0.007)$ and quadruple diameter of graft $(r=0.34, p=0.002)$. BMI and thigh circumference of the patients were not found to correlate with graft size. Male patients were found to have longer semitendinosus graft and larger double and quadruple diameter of the graft. There was no association between the Tegner activity scale and graft size. Regression equations between graft length and quadruple diameter and the anthropometric parameters are also derived. Conclusion: Height, weight and thigh length are useful anthropometric parameters in the prediction of hamstring tendon size. However, the patient's Tegner activity level was not found to be associated with size of the hamstring tendon.
\end{abstract}

Key words: Anterior cruciate ligament, graft, hamstring, semitendinosus, ligament.

\section{Introduction}

Multiple graft choices are available for reconstruction of anterior cruciate ligament (ACL) $[1,2]$. Hamstring tendons are one of the most commonly used autografts for reconstruction because of good strength, ease of harvest and lower donor site morbidity. Whereas a predetermined size of graft can be obtained from bone-patellar-tendon, quadriceps tendon and allografts, size of graft made from the hamstring tendon will depend upon the size of tendons harvested during surgery. Adequate size ACL graft is crucial for providing sufficient strength

*Corresponding author: 1990. souvik@gmail. com and reducing graft failure [3-5]. Thus, it is important to have an estimate of graft length and diameter preoperatively, so that an alternative graft option may be chosen if the expected size of the graft is not adequate. Use of common anthropometric variables may be an easy estimate of graft size if a good correlation exists between them. Several authors have studied the relationship between graft diameter and length and height, weight, body mass index (BMI) and thigh length of the patients $[1,2$, 5-7]. But, none of these studies have studied the relation between the activity level of the individual and graft size. This study prospectively highlights the association of anthropometric parameters (such as age, sex, height, weight, BMI, thigh length and thigh circumference) and activity level of the patients 
Table 1. Demographic and anthropometric details of patients.

\begin{tabular}{|c|c|c|c|c|}
\hline Parameters & Mean & Minimum & Maximum & $\begin{array}{r}\text { Standard } \\
\text { deviation }\end{array}$ \\
\hline Age (years) & 30.2 & 18 & 53 & 8.7 \\
\hline Height $(\mathrm{cm})$ & 168.1 & 144 & 182 & 7.3 \\
\hline Weight (kg) & 72.2 & 47 & 94 & 11.2 \\
\hline Body mass index & 25.6 & 17.3 & 36.3 & 3.7 \\
\hline Thigh length & 46.9 & 37 & 65 & 4.1 \\
\hline Thigh circumference & 47.5 & 36 & 62 & 5.9 \\
\hline $\begin{array}{l}\text { Semitendinosus graft } \\
\text { length }\end{array}$ & 27.7 & 20 & 33 & 2.6 \\
\hline Doubled graft diameter & 6.1 & 4.5 & 7.5 & 0.6 \\
\hline Quadrupled graft diameter & 8.4 & 7 & 10 & 0.7 \\
\hline
\end{tabular}

Table 2. Graft parameters in $\mathrm{mm}$.

\begin{tabular}{lccc}
\hline & Mean graft length & Mean graft double diameter & Mean graft quadruple diameter \\
\hline Male & $27.8 \pm 2.6(20-33)$ & $6.1 \pm 0.6(4.5-7.5)$ & $8.5 \pm 0.7(7-10)$ \\
Female & $27.1 \pm 2.6(21-30)$ & $5.8 \pm 0.56(5-6.5)$ & $7.9 \pm 0.6(7-9)$ \\
$p$ value & 0.39 & 0.03 & 0.02 \\
\hline
\end{tabular}

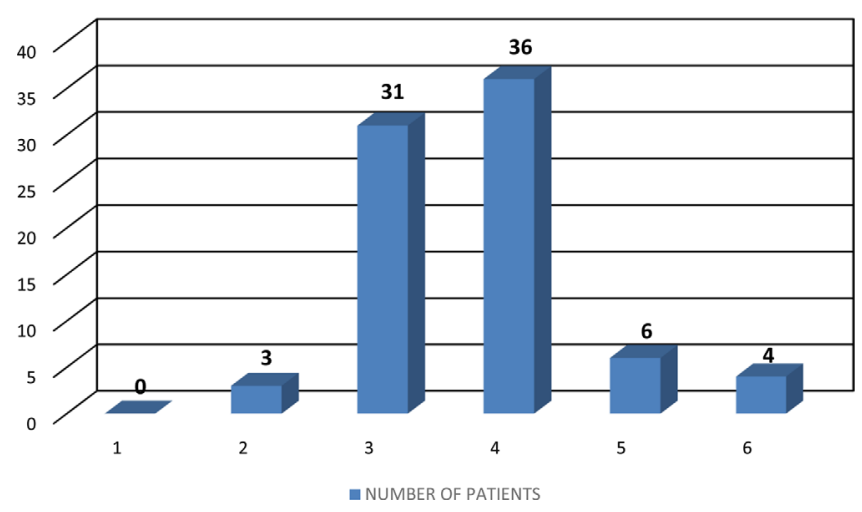

Figure 1. Distribution of Tegner activity scale.

(Tegner activity level) with length and diameter of semitendinosus tendon graft.

\section{Materials and methods}

A total of 95 patients (34 females and 61 males) undergoing arthroscopic ACL reconstruction with ipsilateral autologous hamstring grafts, between January 2017 to October 2018 were included in the study. Patients with medial side knee injury or previous fractures around the knee were excluded. Patients with atrophy of contra-lateral thigh muscles due to any other pathology were also excluded. All patients were operated by the same surgeon. Preoperatively, variables studied were age, sex, height, weight, BMI, thigh circumference (in the bulkiest portion of contralateral thigh approximately $15 \mathrm{~cm}$ above the superior pole of the patella), thigh length (from anterior superior iliac spine to medial joint line), and Tegner activity level before the injury. Intra-operatively, semitendinosus graft was harvested through a standard longitudinal incision over pes anserinus after removing all of its extensions to gastrocnemius. The muscle tissue was then removed to skeletonise the tendon. Length of the tendon was recorded using scale over the graft preparation board between the point of its insertion and a point proximally where it starts to taper. The periosteum of anteromedial tibia harvested along with graft was not taken into account while recording graft length. The diameter of the double and quadruple looped tendon was measured using graft sizing block (Arthrex, 4.5-12 mm holes with $0.5-\mathrm{mm}$ increments), considering the smallest diameter hole the graft could pass through.

\section{Statistical analysis}

Statistical analysis was done using SPSS 24. BMI was calculated using the standard formula using height and weight. Descriptive statistics were obtained for all variables. Correlation between variables was studied using Spearman correlation. One-way ANOVA was used to study the association between sex, Tegner activity level and size of graft.

\section{Results}

Data were obtained from 95 patients with a mean age of 30.2 years (18-53, standard deviation of 8.79$)$. Demographic and anthropometric parameters are summarised in Table 1. Male patients were found to have longer semitendinosus grafts and larger double and quadruple diameter of the graft (Table 2).

Maximum patients (45\%) had a Tegner activity level of 4 (Figure 1). There was no correlation between Tegner activity level and graft length $(r=-0.06, p>0.05, n=74)$, double diameter $(r=-0.07, p>0.05, n=74)$ and quadruple diameter $(r=0.05, p>0.05, n=74)$.

Correlation between graft size and height, weight and thigh length is summarised in Table 3. BMI and thigh circumference of the patients were not found to have correlation with any of the graft parameters. There was a positive correlation between 
Table 3. Correlation between graft parameters and height, weight and thigh length.

\begin{tabular}{lccc}
\hline & \multicolumn{3}{c}{ Pearson correlation coefficient } \\
\cline { 2 - 4 } & Graft length & Double diameter & Quadruple diameter \\
\hline Height & $r=0.41, p<0.001$ & $r=0.29, p=0.008$ & $r=0.30, p=0.006$ \\
Weight & $r=0.34, p=0.002$ & $r=0.2, p=0.06$ & $r=0.34, p=0.002$ \\
Thigh length & $r=0.44, p<0.001$ & $r=0.29, p=0.007$ & $r=0.34, p=0.002$ \\
\hline
\end{tabular}

Table 4. Correlation between graft parameters and height, weight and thigh length in males and females.

\begin{tabular}{|c|c|c|c|c|c|c|}
\hline & \multicolumn{6}{|c|}{ Pearson correlation coefficient } \\
\hline & \multicolumn{2}{|c|}{ Graft length } & \multicolumn{2}{|c|}{ Double diameter } & \multicolumn{2}{|c|}{ Quadruple diameter } \\
\hline & Male & Female & Male & Female & Male & Female \\
\hline Height & $r=0.32, p=0.011$ & $r=0.75, p<0.001$ & $r=0.16, p=0.23$ & $r=0.56, p=0.001$ & $r=0.1, p=0.46$ & $r=0.54, p=0.001$ \\
\hline Weight & $r=0.26, p=0.04$ & $r=0.7, p \leq 0.001$ & $r=0.14, p=0.27$ & $r=0.32, p=0.06$ & $r=0.26, p=0.04$ & $r=0.46, p=0.007$ \\
\hline Thigh length & $r=0.4, p=0.001$ & $r=0.6, p \leq 0.001$ & $r=0.29, p=0.02$ & $r=0.24, p=0.16$ & $r=0.32, p=0.01$ & $r=0.33, p=0.05$ \\
\hline
\end{tabular}

the age of the patient and graft length $(r=0.32, p=0.004$, $n=95)$.

Simple regression analysis revealed the following equations:

Tendon length $(L)=0.212 \times$ thigh length $(\mathrm{TL})(\mathrm{cm})$

$$
\begin{aligned}
& +0.107 \times \text { height }(H)(\mathrm{cm}) \\
& -0.364\left(R^{2}: 0.118, p: 0.002\right),
\end{aligned}
$$

Quadruple diameter $(\mathrm{QD})=0.042 \times$ thigh length $(\mathrm{TL})$

$$
\begin{aligned}
& +0.015 \times \text { weight }(W) \\
& +5.338\left(R^{2}: 0.168, p: 0.000\right) .
\end{aligned}
$$

Graft parameters of male patients and female patients were analysed separately. The correlation has been tabulated in Table 4.

Simple regression equations for male and female patients separately are as follows:

For male patients:

$$
\begin{aligned}
\text { Tendon length }(L)= & 0.226 \times \text { thigh length }(\mathrm{TL})(\mathrm{cm}) \\
& +0.111 \times \text { height }(H)(\mathrm{cm}) \\
& -1.75\left(R^{2}: 0.232, p: 0.000\right),
\end{aligned}
$$

Quadruple diameter $(\mathrm{QD})=0.042 \times$ thigh length $(\mathrm{TL})$

$$
\begin{aligned}
& +0.01 \times \text { weight }(W) \\
& +5.822\left(R^{2}: 0.126, p: 0.000\right) .
\end{aligned}
$$

For female patients:

$$
\begin{aligned}
\text { Tendon length }(L)= & 0.155 \times \text { height }(H)(\mathrm{cm})+0.094 \\
& \times \text { weight }(W)(\mathrm{kg}) \\
& -4.536\left(R^{2}: 0.657, p: 0.000\right),
\end{aligned}
$$

Quadruple diameter $(\mathrm{QD})=0.039 \times$ height $(H)(\mathrm{cm})$

$$
+1.585\left(R^{2}: 0.295, p: 0.001\right) \text {. }
$$

\section{Discussion}

Hamstring tendon grafts are one of the most popular autograft choices in ACL reconstruction. But their length and diameter may be unpredictable. Biomechanical studies have shown increased strength and stiffness of a hamstring graft with increased graft diameter [3, 4]. Patients having graft diameter of more than $8 \mathrm{~mm}$ have been shown to have lesser revision rates and graft failures $[8,9]$. Female patients were found to have lesser graft lengths and diameters compared to male patients (Table 2). This finding has been reported by several authors previously. Need for estimating graft length and diameter preoperatively may be more important in female patients. Height is the most predictable indicator of graft diameter and length in the literature $[2,5-7,10-12]$. This study showed a strong correlation between height and graft length $(r=0.41$, $p<0.001)$, double diameter $(r=0.29, p=0.008)$ and quadruple diameter $(r=0.3, p<0.001)$. A statistically significant correlation between weight and graft length $(r=0.34, p=0.002)$ and quadruple diameter $(r=0.34, p=0.002)$ was also noted, which has been reported in only a few studies [2, 7, 11]. BMI did not show any correlation with the graft parameters. Leg length has been found to have a role in predicting the graft parameters in the literature $[12,13]$. Thigh-length was taken as an anthropometric parameter in this study, which has been rarely described in previous studies [14, 15]. It was found to be significantly correlating with graft length $(r=0.44$, $p<0.001)$, double $(r=0.29, p=0.007)$ and quadruple diameter ( $r=0.35, p=0.002$ ) (Figure 2). Thus, thigh-length might be easy to measure and sensitive tool for the prediction of graft length and diameter. Naiyer et al. [6] had shown thigh circumference as a predictive parameter, but their result has not been replicated in this study or any other previous studies $[7,11,16]$.

Correlation between Tegner activity scale and graft parameters was also evaluated, which has not been studied before. It is plausible that patients with higher activity levels may have larger tendon sizes. No significant correlation was found between the two. 


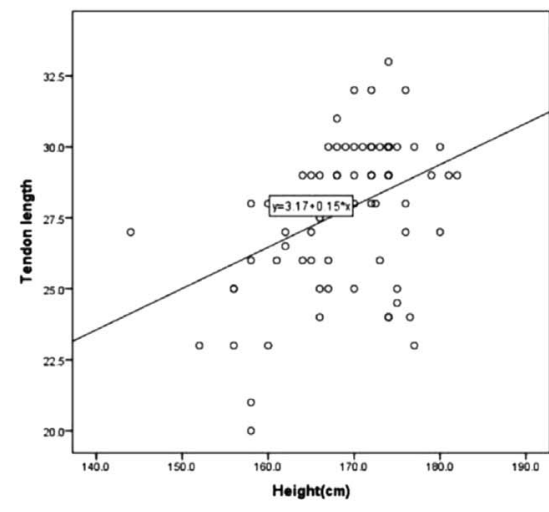

a

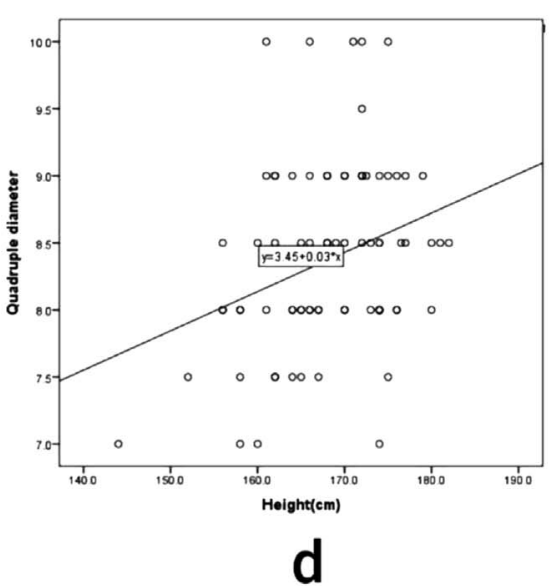

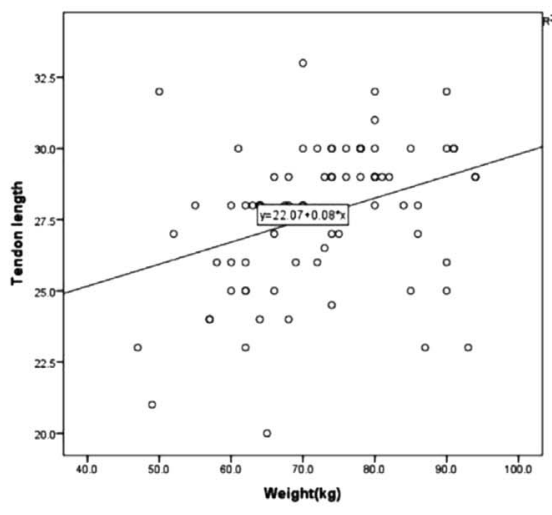

b

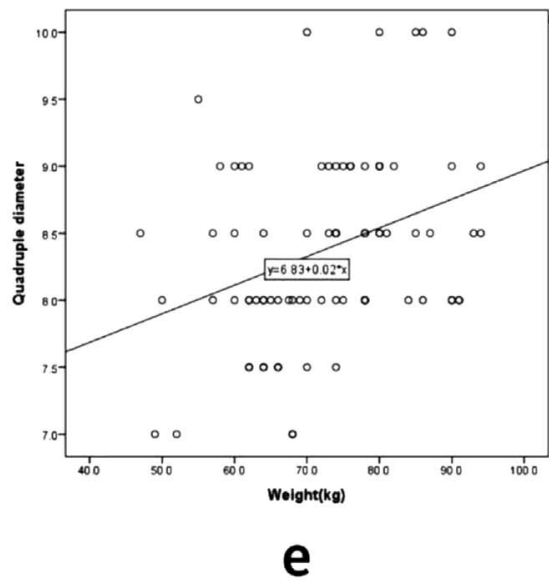

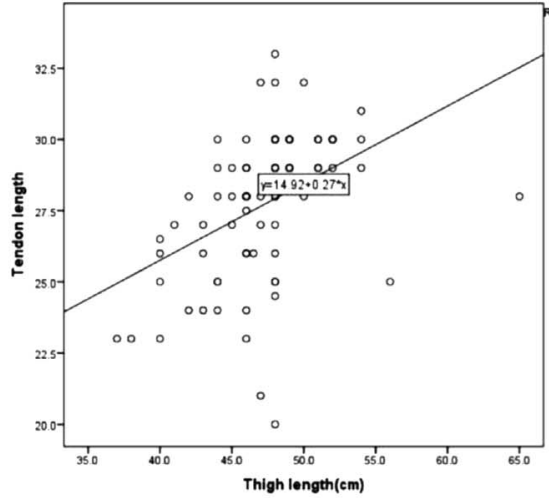

C

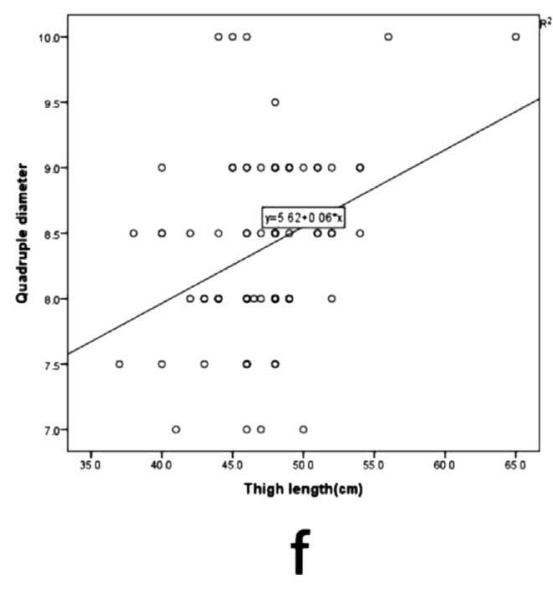

Figure 2. Scatter plots showing correlations of tendon length to height (a), weight (b) and thigh length (c) and also correlations of quadruple diameter to height (d), weight (e) and thigh length (f).

The study also highlights easy and reliable regression equations for pre-operatively determining the tendon lengths and quadruple diameter from these data.

$$
\begin{gathered}
L=0.212 x \mathrm{TL}(\mathrm{cm})+0.107 x H(\mathrm{~cm})=0.364, \\
\mathrm{QD}=0.042 x \mathrm{TL}+0.015 x W+5.338 .
\end{gathered}
$$

Separate simple regression equations for both male and female patients could also be formulated as stated below:

$$
\begin{aligned}
& \text { For male patients }: L=0.226 \times \mathrm{TL}(\mathrm{cm})+0.111 \times H(\mathrm{~cm}) \\
& -1.75, Q D=0.042 \times T L+0.01 \times W+5.822 ; \\
& \text { For female patients }: L=0.155 \times H(\mathrm{~cm})+0.094 \\
& \times W(\mathrm{~kg})-4.536, Q D=0.039 \times H(\mathrm{~cm})+1.415
\end{aligned}
$$

The findings from this study suggest that to achieve a quadruple-diameter of $8 \mathrm{~mm}$ with isolated semitendinosus tendon, the patient should have $155 \mathrm{~cm}$ height, $58 \mathrm{~kg}$ weight and $40 \mathrm{~cm}$ thigh length. Thus considering gender-specific equations, a female patient should have $168 \mathrm{~cm}$ height and a male patient should have $60 \mathrm{~kg}$ weight and $38 \mathrm{~cm}$ thigh length to obtain a quadruple graft diameter of $8 \mathrm{~mm}$. According to the dataset, thigh-length has proven to be a more useful predictor in case of males, whereas height was correlating more significantly in females. This can help to avoid the intraoperative complication of having a small hamstring tendon. The patient can be counseled well before surgery about the need for any other tendon as a graft option. This study is important because data on the correlation of anthropometric parameters from Indian population are limited $[6,12]$, and no previous studies have studied the effect of activity level of the patient on graft parameters and sexual differences in graft sizes. Finally, the data were unique as all the grafts were harvested by the same surgeon and following the same technique without any chances of bias.

\section{Conclusion}

The ability to predict the graft parameters preoperatively is undeniably useful. Common anthropometric parameters like height have been proven useful in several studies. However, this study found the weight of the patient and thigh length also as good predicting parameters for quadruple diameter and length of the graft. Pre-injury Tegner activity level fails to prove a useful parameter. Male patients with height lesser than $155 \mathrm{~cm}$, weight lesser than $58 \mathrm{~kg}$ and thigh length lesser than $40 \mathrm{~cm}$ are not only at risk of a thinner graft, but also the tendon length may be shorter needing alternative graft options. 


\section{Conflict of interest}

The author(s) declared no potential conflicts of interest with respect to the research, authorship, and/or publication of this article.

\section{References}

1. Pereira RN, Karam FC, Schwanke RL, Millman R, Foletto ZM, Schwanke CHA (2016) Correlation between anthropometric data and length and thickness of the tendons of the semitendinosus and gracilis muscles used for grafts in reconstruction of the anterior cruciate ligament. Rev Bras Ortop 51(2), 175-180.

2. Ma CB, Keifa E, Dunn W, Fu FH, Harner CD (2010) The Knee Can pre-operative measures predict quadruple hamstring graft diameter? Knee 17(1), 81-83.

3. Handl M, Držík M, Cerulli G, et al. (2007) Reconstruction of the anterior cruciate ligament: dynamic strain evaluation of the graft. Knee Surg Sports Traumatol Arthrosc 15(3), 233-241.

4. Hamner DL, Brown CH, Steiner ME, Hecker AT, Hayes WC (2018) Hamstring tendon grafts for reconstruction of the anterior cruciate ligament: biomechanical evaluation of the use of multiple strands and tensioning techniques. J Bone Joint Surg Am 81(4), 549-557.

5. Tuman JM, Diduch DR, Rubino LJ, Baumfeld JA, Nguyen HS, Hart JM (2007) Predictors for hamstring graft diameter in anterior cruciate ligament reconstruction. Am J Sports Med 35 (11), 1945-1949.

6. Asif N, Ranjan R, Ahmed S, Sabir AB, Jilani LZ, Qureshi OA (2016) Prediction of quadruple hamstring graft diameter for anterior cruciate ligament reconstruction by anthropometric measurements. Indian J Orthop 50, 49-54.

7. Çeliktafi M, Gölpinar A, Köse Ö, Sütoluk Z, Çelebi K, Sarpel Y (2013) Prediction of the quadruple hamstring autograft thickness in ACL reconstruction using anthropometric measures. Acta Orthop Traumatol Turc 47(1), 14-18.
8. Magnussen RA, Lawrence JTR, West RL, Toth AP, Taylor DC, Garrett WE (2012) Graft size and patient age are predictors of early revision after anterior cruciate ligament reconstruction with hamstring autograft. Arthrosc J Arthrosc Relat Surg 28(4), 526-531.

9. Mariscalco MW, Flanigan DC, Mitchell J, et al. (2013) The influence of hamstring autograft size on patient-reported outcomes and risk of revision after anterior cruciate ligament reconstruction: a Multicenter Orthopaedic Outcomes Network (MOON) cohort study. Arthrosc J Arthrosc Relat Surg 29(12), 1948-1953.

10. Conte EJ, Hyatt AE, Gatt Jr. CJ, Dhawan A (2018) Hamstring autograft size can be predicted and is a potential risk factor for anterior cruciate ligament reconstruction failure. Arthrosc J Arthrosc Relat Surg 30(7), 882-890.

11. Thomas S, Bhattacharya R, Saltikov JB, Kramer DJ (2013) Influence of anthropometric features on graft diameter in ACL reconstruction. Arch Orthop Trauma Surg, 133(2), 215-218.

12. Gupta R, Malhotra A, Masih GD, Khanna T (2017) Equationbased precise prediction of length of hamstring tendons and quadrupled graft diameter by various anthropometric variables for knee ligament reconstruction in Indian population. J Orthop Surg 25(1), 1-10.

13. Schwartzberg R, Burkhart B, Lariviere C (2018) Prediction of hamstring tendon autograft diameter and length for anterior cruciate ligament reconstruction. Am J Orthop (Belle Mead NJ) 37(3), 157-159.

14. Goyal S, Matias N, Pandey V, Acharya K (2016) Are preoperative anthropometric parameters helpful in predicting length and thickness of quadrupled hamstring graft for ACL reconstruction in adults? A prospective study and literature review. Int Orthop 40(1), 173-181.

15. Treme G, Diduch DR, Billante MJ, Miller MD, Hart JM (2008) Hamstring graft size prediction: a prospective clinical evaluation. Am J Sports Med 36(11), 2204-2209.

16. Schwartzberg R, Burkhart B, Lariviere C (2008) Prediction of hamstring tendon autograft diameter and length for anterior cruciate ligament reconstruction. Am J Orthop 37(3), 157-159.

Cite this article as: Goyal T, Paul S, Das L \& Choudhury AK (2020) Correlation between anthropometric measurements and activity level on length and diameter of semitendinosus tendon autograft in knee ligament surgery: A prospective observational study. SICOT-J 6, 23 